\title{
Modeling the arsenic biosensor system
} Yizhi Cai*1, Bryony Davidson², Hongwu $\mathrm{Ma}^{3}$ and Chris French ${ }^{4}$

Address: ${ }^{1}$ Virginia Bioinformatics Institute, Virginia Tech, the University of Edinburgh, UK, ${ }^{2}$ School of Engineering, the University of Edinburgh, UK, ${ }^{3}$ School of Informatics, the University of Edinburgh, UK and ${ }^{4}$ School of Biology, the University of Edinburgh, UK

Email: Yizhi Cai* - caiyizhi@gmail.com

* Corresponding author

from BioSysBio 2007: Systems Biology, Bioinformatics and Synthetic Biology

Manchester, UK. II-13 January 2007

Published: 8 May 2007

BMC Systems Biology 2007, I(Suppl I):P83 doi:I0.I 186/1752-0509-I-SI-P83

This abstract is available from: http://www.biomedcentral.com/ I752-0509/I? issue=S I

(c) 2007 Cai et al; licensee BioMed Central Ltd.

This paper reports the modeling part of an arsenic biosensor system, which was the iGEM project accomplished in the University of Edinburgh 2006. The arsenic biosensor system sought to address the fatal water pollution problem occurring in many poor countries/areas like Bangladesh by producing calibratable $\mathrm{pH}$ changes in response to a range of arsenic concentrations. An ODE based computational model which contains 3 operons, 19 reactions and 17 species has been constructed in order to shed light on the wet-lab experimental design. The model showed good induction of urease and repression of lacZ in the absence of arsenate, and repression of urease and induction of lac $Z$ at high arsenate levels. By analyzing the sensitivity of each parameter/species, we identified their relative importance in the system which gives the theoretical guide when measuring the variable in wet-lab. 